Pacific Journal of Mathematics

ON AN ENTIRE FUNCTION OF AN ENTIRE FUNCTION 


\title{
ON AN ENTIRE FUNCTION OF AN ENTIRE FUNCTION DEFINED BY DIRICHLET SERIES
}

\author{
K. N. SRIVAStava
}

In this note we prove the following theorem which seems to exhibit an essential property of the order $(R)$ of entire function defined by Dirichlet series.

Theorem If $h(s)$ and $g(s)$ are entire functions defined by Dirichlet series and $g(\log h(s))$ is an entire function of finite order $(R)$, then there are only two possible cases: either

(a) the internal function $h(s)$ is a Dirichlet polynomial and the external function $g(s)$ is of finite order $(R)$; or

(b) the internal function $h(s)$ is of finite order $(R)$ and the external function $g(s)$ is of order zero.

Here $h(s)$ and $g(s)$ are entire functions defined by the Dirichlet series

$$
\begin{aligned}
& h(s)=\sum_{n=1}^{\infty} a_{n} e^{\lambda_{n} s}, \\
& g(s)=\sum_{n=0}^{\infty} b_{n} e^{n s},
\end{aligned}
$$

satisfying the relations

$$
\begin{aligned}
& \underset{-\infty<t<\infty}{\operatorname{l.u.b.}}|h(\sigma+i t)|=H(\sigma), \\
& \underset{-\infty<t<\infty}{\text { l.u.b. }}|g(\sigma+i t)|=G(\sigma),
\end{aligned}
$$

for any real value of (in particular, every Dirichlet series absolutely convergent in the whole plane will have this property).

For this type of function Ritt [2] defines the order in the following way:

$$
\rho=\lim _{\sigma=\infty} \sup \frac{\log \log H(\sigma)}{\sigma}
$$

will be called the order $(R)$ of $h(s)$; we shall also express it by saying that $h(s)$ is of order $(R)$ equal to $\rho$.

It is to be noted that since $g(\log h(s))$ is simply a power series in $h(s)$, it is a single valued function. Since $h(s)$ is an entire function, there will be at least one term of the series which is greater than all other terms in its absolute value. In the case when there are more than one such terms we regard the term with the highest rank as the maximum term. With this convention the maximum term of $h(s)$ will be denoted by $\mu(\sigma, h)$.

2. For the proof of the above theorem we require following lemmas. 
LEMMA 1. If $h(s)$ is an entire function defined by Dirichlet series with least upper bound $H(\sigma)$ and maximum term $\mu(\sigma, h)$, then

$$
H(\sigma) \geqq \mu(\sigma, h) \geqq\left|a_{n}\right| e^{\lambda_{n} \sigma} .
$$

Sugimura [3] has proved this result.

Lemma 2. Suppose that $\theta$ is any number $0<\theta<\infty$ and

$$
w=\phi(s)=\sum_{n=1}^{\infty} a_{n} e^{\lambda_{n} s},\left(s=\sigma+i t, 0<\lambda_{1}<\lambda_{2} \cdots \rightarrow \infty\right)
$$

is any function regular for $R e(s) \leqq \sigma$ and is representable by an absolutely convergent Dirichlet series. Furthermore suppose that $\phi(s)$ satisfies the conditions

$$
\phi(-\infty)=0, \underset{\substack{R e(s)=\sigma-\theta \\-\infty<t<\infty}}{\text { l.u.b. }}|\phi(s)|=1 .
$$

Let $r_{\phi}$ denote the radius of the largest circle $|w|=r_{\phi}$ all of whose points represent the values taken by $\phi(s)$ in the domain $\operatorname{Re}(s) \leqq \sigma$. Then $r_{\phi}$ is not less than $C, C=C\left(\lambda_{1}, \theta\right)$ being a positive number which depends on $\lambda_{1}$ and $\theta$.

This lemma is a generalization of a result of Bohr [1] which runs as follows:

Suppose that $\mu$ is any number, $0<\mu<1$, and $w=\phi(z)$ is any function which is regular for $|z| \leqq 1$ and satisfies the conditions

$$
\phi(0)=0, \operatorname{Max}_{|z|=\mu}|\phi(z)|=1 .
$$

Let $r_{\phi}$ be the radius of the largest circle $|w|=r_{\phi}$ all of whose points represent the values taken by $\phi(z)$ in the circular domain $|z| \leqq$ 1. Then $r_{\phi}$ is not less than a positive number $C, C=C(\mu)$ which depends on $\mu$.

The simplest proof that I can present is based on a theorem of Ritt [2] which is a generalization of Landau-Schottky's theorem.

Proof of Lemma 1. The theorem of Ritt which we need runs as follows: Let

$$
\psi(s)=a_{0}+\sum_{n=1}^{\infty} a_{n} e^{\lambda_{n} s},\left(s=\sigma+i t, 0<\lambda_{1}<\lambda_{2} \cdots \infty\right)
$$

be analytic for $\operatorname{Re}(s) \leqq \sigma$ and for $R e(s) \leqq T \leqq \sigma$ be representable by an absolutely convergent Dirichlet series. Let $\theta$ be a variable assuming all values greater than zero, and $\psi(s)$ is nowhere zero or unity for $R e(s) \leqq \sigma$. Then there exists a function $S\left(\alpha_{0}, \lambda_{1}, \theta\right)$, such that

$$
|\psi(s)|<S\left(a_{0}, \lambda_{1}, \theta\right) \text { for } \operatorname{Re}(s) \leqq \sigma-\theta \text {. }
$$


A simple modification will show that if $|\psi(-\infty)| \leqq 1$ then there exists a function $S\left(\lambda_{1}, \theta\right)$, such that $|\psi(s)|<S\left(\lambda_{1}, \theta\right)$. In particular this is true, if $a_{0}=-1$.

From the result stated above follows the existence of a number $C=C\left(\lambda_{1}, \theta\right)$ in the sense of the lemma, if we take $C\left(\lambda_{1}, \theta\right)=$ $1 / 1+3 S\left(\lambda_{1}, \theta\right)$. For if we suppose that the lemma is false, then for $R e(s) \leqq \sigma$ there exists a regular function $\phi(s)$ with $\phi(-\infty)=0$ and l.u.b. $\underset{-\infty<t<\infty}{R e(s)=\sigma-\theta}|\phi(s)|=1$, for which the radius $r_{\phi}<C$. This means that $\phi(s)$ does not take all values on the circle $|w|=C$ and also on the circle $|w|=2 C$. In particular it does not assume the values $a=C . e^{i \alpha}$ and $b=2 C . e^{i \beta}$ respectively. Let

$$
\psi(s)=\frac{\phi(s)-a}{b-a} .
$$

$\psi(s)$ is regular for $R e(s) \leqq \sigma$ and is representable by an absolutely convergent Dirichlet series and does not take the values zero or unity. Further

$$
|\psi(-\infty)|=\left|\frac{\phi(-\infty)-a}{b-a}\right| \leqq 1 .
$$

Hence from the theorem of Ritt, there exists a function $S\left(\lambda_{1}, \theta\right)$ such that for $R e(s) \leqq \sigma-\theta$

$$
|\psi(s)|<S\left(\lambda_{1}, \theta\right)
$$

Hence for $R e(s) \leqq \sigma-\theta$

$$
|\phi(s)|=|a+(b-a) \psi(s)|<C+3 C . S\left(\lambda_{1}, \theta\right)<1,
$$

which is contrary to the hypothesis that

$$
\underset{\substack{\text { l.ue } \\ \text { Res }(s)=\sigma-\theta \\-\infty<t<\infty}}{\cos }|\phi(\sigma+i t)|=1 \text {. }
$$

Lemma 3. Suppose that $f(s), g(s)$ and $h(s)$ are entire functions connected by the relation

$$
f(s)=g(\log h(s)),
$$

suppose further that

$$
h(-\infty)=0 .
$$

Let $F(\sigma), G(\sigma)$ and $H(\sigma)$ denote the least upper bounds of $f(s), g(s)$ and $h(s)$ respectively for $R e(s)=\sigma$. Then there exists a definite number $C$ independent of $g(s), h(s)$ and $\sigma$, such that

$$
F(\sigma) \geqq G\{\log (C \cdot H(\sigma-\theta))\}
$$


where $\theta$ is a fixed constant.

Proof of Lemma 3. To fix the ideas, we take $\theta$ to be a fixed positive constant, and apply Lemma 2 to the function

$$
z=\phi(s)=\frac{h(s)}{H(\sigma-\theta)}
$$

which satisfies the conditions (1). We see that this function maps the domain $R e(s) \leqq \sigma$ on a Riemann surface over the $z$-plane whose various sheets cover the whole periphery of a certain circle of centre $z=0$ and radius $R, R$ being not less than $C . H(\sigma-\theta)$. Furthermore, the function $w=\log z$ maps a Riemann surface consisting of infinity of sheets, each cut along the negative real axis from $-R$ to zero and the upper half of each sheet is joined to the lower half of the next, on the $w$-plane extending from $-\infty$ to $\operatorname{Re}(w)=\log R$. Thus a strip of width $2 \Pi$ corresponds to one complete sheet of the Riemann surface and every point of Riemann surface corresponds to just one point of $w$-plane. $R$ being not less than $C . H(\sigma-\theta)$.

Suppose that $w_{0}$ is a point on the line $R e(w)=\log R$, such that

$$
g\left(w_{0}\right)=G\left\{\operatorname{Re}\left(w_{0}\right)\right\}=G(\log R),
$$

then there is at least one point $s_{0}$ inside $R e(s) \leqq \sigma$, such that

$$
w_{0}=\log h\left(s_{0}\right) \text {. }
$$

Hence it follows that

$$
G[\log \{C . H(\sigma-\theta)\}] \leqq G\left\{R e\left(w_{0}\right)\right\}=\left|g\left(w_{0}\right)\right|=\left|g\left(\log h\left(s_{0}\right)\right)\right| \leqq F(\sigma) .
$$

3. Proof of the theorem. We observe that $F(\sigma), G(\sigma)$ and $H(\sigma)$ are increasing functions. We may express the hypothesis that $f(s)$ is of finite order $(R)$ ' $a$ ' by the inequality

$$
F(\sigma)<\exp [\exp \{\sigma(\alpha+\varepsilon)\}] \text {. }
$$

We have

$$
h(s)=a_{1} e^{\lambda_{1} s}+a_{2} e^{\lambda_{2} s}+\cdots+a_{m} e^{\lambda_{m} s}+\cdots .
$$

From Lemma 1, we have

$$
H(\sigma) \geqq \mu(\sigma, h) \geqq\left|a_{m}\right| e^{\lambda_{m} \sigma} .
$$

In virtue of (9), (10) and (11)

$G\left[\log \left\{C .\left|a_{m}\right| e^{-\lambda_{m} \theta}\right\}+\lambda_{m} \sigma\right] \leqq G[\log \{C . H(\sigma-\theta)\}]<\exp [\exp \{\sigma(a+\varepsilon)\}]$ $G\left[\log \left\{C .\left|a_{m}\right| e^{-\lambda_{m} \theta}+\sigma\right]<\exp \left[\exp \left\{(\alpha+\varepsilon) \sigma / \lambda_{m}\right\}\right]\right.$. 
That is to say, the order $(R)$ of $g(s)$ does not exceed $a / \lambda_{m}$. If $h(s)$ is not a Dirichlet polynomial, $\lambda_{m}$ can be chosen arbitrarily large and in this case the order $(R)$ of $g(s)$ is zero.

In any case there is an inequality for $g(s)$, analogous to (11), let us say

$$
G(\sigma) \geqq\left|b_{n}\right| e^{n \sigma}(n \geqq 1) .
$$

Combining this with (9) and (10), we obtain

$$
\begin{aligned}
& \left|b_{n}\right| \exp [n \log \{C \cdot H(\sigma-\theta\}] \leqq G[\log \{C \cdot H(\sigma-\theta)\}] \\
& \quad \leqq F(\sigma)<\exp [\exp \{(a+\varepsilon) \sigma\}] .
\end{aligned}
$$

Thus the order $(R)$ of $h(s)$ is not greater than ' $a$ '.

I am thankful to the referee for his useful suggestions.

\section{REFERENCES}

1. H. Bohr, Uber einen Staz von Edmund Landau, Scripta Univ atque Bibl Hierosolymitanarum, (2) 1 (1923).

2. J. M. Ritt, On certain points in the theory of Dirichlet series, Amer. J. Math, 50 (1928), 73.

3. K. Sugimura, Ubertragung einiger Satze and der Theorie der ganzen Funktionen auf Dirichletschen Reihen, Math. Zeit 29 (1929), 264.

Received March 11, 1965.

M. A. College of Technology

BHoPAL (M. P) INDIA 



\section{PACIFIC JOURNAL OF MATHEMATICS}

\section{EDITORS}

H. SAMELSON

Stanford University

Stanford, California

R. M. BLUMENTHAL

University of Washington

Seattle, Washington 98105

\section{*J. DugundJI}

University of Southern California Los Angeles, California 90007

RICHARD ARENS

University of California

Los Angeles, California 90024

\section{ASSOCIATE EDITORS}

E. F. BECKENBACH
F. WOLF

K. YosIDA

\section{SUPPORTING INSTITUTIONS}

\author{
UNIVERSITY OF BRITISH COLUMBIA \\ CALIFORNIA INSTITUTE OF TECHNOLOGY \\ UNIVERSITY OF CALIFORNIA \\ MONTANA STATE UNIVERSITY \\ UNIVERSITY OF NEVADA \\ NEW MEXICO STATE UNIVERSITY \\ OREGON STATE UNIVERSITY \\ UNIVERSITY OF OREGON \\ OSAKA UNIVERSITY \\ UNIVERSITY OF SOUTHERN CALIFORNIA
}

\author{
STANFORD UNIVERSITY \\ UNIVERSITY OF TOKYO \\ UNIVERSITY OF UTAH \\ WASHINGTON STATE UNIVERSITY \\ UNIVERSITY OF WASHINGTON \\ AMERICAN MATHEMATICAL SOCIETY \\ CHEVRON RESEARCH CORPORATION \\ TRW SYSTEMS \\ NAVAL ORDNANCE TEST STATION
}

Mathematical papers intended for publication in the Pacific Journal of Mathematics should be typewritten (double spaced). The first paragraph or two must be capable of being used separately as a synopsis of the entire paper. It should not contain references to the bibliography. Manuscripts may be sent to any one of the four editors. All other communications to the editors should be addressed to the managing editor, Richard Arens at the University of California, Los Angeles, California 90024 .

50 reprints per author of each article are furnished free of charge; additional copies may be obtained at cost in multiples of 50 .

The Pacific Journal of Mathematics is published monthly. Effective with Volume 16 the price per volume (3 numbers) is $\$ 8.00$; single issues, $\$ 3.00$. Special price for current issues to individual faculty members of supporting institutions and to individual members of the American Mathematical Society: $\$ 4.00$ per volume; single issues $\$ 1.50$. Back numbers are available.

Subscriptions, orders for back numbers, and changes of address should be sent to Pacific Journal of Mathematics, 103 Highland Boulevard, Berkeley 8, California.

Printed at Kokusai Bunken Insatsusha (International Academic Printing Co., Ltd.), No. 6, 2-chome, Fujimi-cho, Chiyoda-ku, Tokyo, Japan.

PUBLISHED BY PACIFIC JOURNAL OF MATHEMATICS, A NON-PROFIT CORPORATION

The Supporting Institutions listed above contribute to the cost of publication of this Journal, but they are not owners or publishers and have no responsibility for its content or policies.

* Paul A. White, Acting Editor until J. Dugundji returns. 


\section{Pacific Journal of Mathematics}

\section{Vol. 18, No. 2 \\ April, 1966}

Alexander V. Arhangelskii, On closed mappings, bicompact spaces, and a problem of P. Aleksandrov .............................. 201

A. K. Austin, A note on loops . . . . . . . . . . . . . . . . . . . . . . . . . . . . 209

Lawrence Peter Belluce and William A. Kirk, Fixed-point theorems for families of contraction mappings...................... 213

Luther Elic Claborn, Every abelian group is a class group ............ 219

Luther Elic Claborn, A note on the class group .................. 223

Robert Stephen De Zur, Point-determining homomorphisms on multiplicative semi-groups of continuous functions............. 227

Raymond William Freese, A convexity property ................ 237

Frederick Paul Greenleaf, Characterization of group algebras in terms of their translation operators ......................... 243

Andrzej Hulanicki, On the spectral radius of hermitian elements in group algebras....................................... 277

Michael Bahir Maschler and Bezalel Peleg, A characterization, existence proof and dimension bounds for the kernel of a game ............ 289

Yiannis (John) Nicolas Moschovakis, Many-one degrees of the predicates

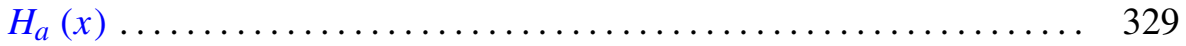

G. O. Okikiolu, $n$th order integral operators associated with Hilbert transforms.

C. E. Rickart, Analytic phenomena in general function algebras ... 361

K. N. Srivastava, On an entire function of an entire function defined by Dirichlet series

Paul Elvis Waltman, Oscillation criteria for third order nonlinear differential equations .......................... 